\title{
Semantic Peculiarities of the Verbs with the Highest Degree of Polysemy Denoting Conflict Actions
}

\author{
Oksana Ivanivna Myhalets \\ Department of English Philology, \\ Faculty of Foreign Philology, \\ State University "Uzhhorod National University”, \\ Uzhhorod, Ukraine
}

Doi: 10.36941/ajis-2020-0038

\begin{abstract}
The purpose of the article is to conduct a lexico-semantic analysis of the language units denoting conflict actions in modern English. Our task is to find out the semantic peculiarities of the polysemantic verbs in the language under study, which form the group of words denoting conflict actions with the highest degree of polysemy. The research has been carried out with the help of the system and structural approach, based on a combination of the formalized analysis of lexical semantics with linguistic methods of research. Such a combination is necessary for revealing the system and structural organization of lexical units denoting conflict actions and their inner mechanisms of functioning in modern English. As a result, the degree of the semantic relativity of the language units denoting conflict actions as well as the character of the semes' functionality have been revealed. In addition, both common and distinctive features, quantitative and qualitative characteristics of the verbs' semantics in the language under study have been disclosed. Complex lexico-semantic analysis of the language units denoting conflict actions in English gave the opportunity to treat them as phenomena of person's everyday life and activities as well as to find out different ways and means of their language expressions by means of the matrix.
\end{abstract}

Keywords: lexical semantics, language units, formalized analysis, common and distinctive features, qualitative and quantitative characteristics

\section{Introduction}

Language is an inalienable attribute of human existence, the product of person's spiritual activity, while acting as its instrument and the material. At the same time, each language is unique and with its help, person gets to know the world around, acquires knowledge about it. Language is not only an "instrument for conveying meaning" (Simpson \& Weiner, 1989, p. 3), but also a social phenomenon. In other words, language is "all at once a tool and the mechanism that determines how we relate to the world, to each other, and, even to ourselves" (Nordquist, 2019). Language is "what makes us human" (Nordquist, 2019).

The English language is used not only to meet everyday needs and so the range of its usage is extremely wide. The studied language system reflects all without exception spheres of people's life, their mentality, culture, specificity of being, etc. To the human being we include their behaviour, actions, dreams, aspirations and desires which are inseparably linked with the conflict actions.

Due to the fact that conflict actions are everyday processes of human life, they are in close 
relations with the society, taking one of the present time key positions. Conflict actions signal about the expression of dissatisfaction, hatred, fury, argument, debate, animosity between individuals that is why sometimes the desire to defeat an opponent becomes more important than the desire to resolve the problem. At the same time, thanks to the conflict, people ease tension in a relationship, it is a motive force for the necessary changes, guarantees the forward society movement, forms a necessary socially balance and so on.

Semantics takes the very important place in the language study, as it plays a decisive role in social background of every person, the need to understand it becomes more obvious and more urgent. Semantics "is the study of meaning communicated through language" (Allan, 2016, p. 153). It is also "at the centre of the human mind study which is closely bound up with the way we classify and convey our world experience through language” (Fabian, 2017, pp. 11-12). And so the language's lexis has at different times been of interest to scientists so far as it is most sensible to changes occurring in person's everyday life and in society as a whole. These changes affect human's ways of life, relations, culture, which contains manners and norms of behaviour, traditions, customs etc.

The study of the specificity of the words denoting conflict actions in the English language is an urgent problem of modern linguistics, which is determined by a number of reasons. First, it is a heightened interest in studying negative actions which concern human and non-human beings, especially in today's world, when we see different types of conflicts and not always successful attempts to resolve them. Secondly, the importance of the conflict actions' study is dictated by the absence of special works that would represent the peculiarities of lexical semantics of the verbs denoting conflict actions in English. Third, a comprehensive study of different types of conflict actions will promote better and deeper understanding of their nature and it will be easier to identify all possible ways of resolving the problem.

The multidimensional conflict manifestation, its forms and means of expression have increased the interest in its complex study both in linguistics and other related and non-related sciences such as: sociolinguistics, pragmatics, psycholinguistics, communicative linguistics, sociology, political science, psychology, philosophy, culturology, mathematics, history, conflictology, etc.

In modern linguistics, scientific researchers mainly deal with the study of communicative conflict situations and conflict language behaviour (Arieli, 2015; Baumann et al., 2016), and some aspects of conflict semantics (Abdou \& Keiding, 2019; Burbekova \& Nurzhanova, 2014). Much attention of modern researchers is focused on the problem of ethnic (Charalambous, Zembylas \& Charalambous, 2016; Euwema \& Van Emmerik, 2007; Glass \& Cook, 2017; Lebedko, 2014; Massey \& Miller, 2018; Volpe et al., 2019), political and military (Abu-Bader \& Ianchovichina, 2019; Berry \& Berrang-Ford, 2016; Ran \& Zhao, 2018; Thiessen \& Darweish, 2018) conflicts. Some studies are devoted to the conflict management (Aguirre, 2016; Melin, 2016; Naveh-Kedem \& Sverdlik, 2019).

The psychology of conflict was studied by researchers De Dreu and Gelfand (2008) in their book “The Psychology of Conflict and Conflict Management in Organizations". Throughout the book, authors define conflict as "a process that begins when an individual or group perceives differences and opposition between itself and another individual or group about interests and resources, beliefs, values, or practices that matter to them" (De Dreu \& Gelfand, 2008, p. 6) The authors focus their attention on the study of conflict and its management in organizations, affirming that "close connection between conflict and collaborative work has becomes even stronger due to a variety of changes in the world of work and organizations" (De Dreu \& Gelfand, 2008, pp. 3-4).

In the study of conflict actions, special attention is paid to the semiotics, which deals with "the study of signs" (Chandler, 2017, p. 1) and sign processes. Semiotic conflict arises when a symbol can represent multiple thoughts.

Studying of the conflict signs and conflict transformations, representatives of semiotics affirm that this science is "a helpful tool for understanding conflict" (Sarpiya, 2018, p. 1), because "paying close attention to signs of conflict can then be helpful. Some early symptoms of conflict are subtle" (Sarpiya, 2018, p. 11). Conflict usually begins with the distrust between individuals and manifests itself through communication break downs, blaming someone for something and accusing somebody of 
something. Therefore, early identification of conflict actions' symptoms may prevent their occurrence or help to find the constructive ways out of the situation.

As language is a sign system, then the appeal to semiotics for the study of lexical units denoting conflict actions is necessary. At first sight, it seems quite easy to determine the objective and sense meanings of different linguistic units. However, it's not so. Many conflicts between people arise precisely because they can not clearly define the structure of word meanings being used. This situation is due to the fact that people often use polysemantic lexical units in language and speech.

In spite of a large number of works dedicated to conflict study, the issue of conflict actions, their forms and means of expression in modern English with the help of verbs still remains unresolved. In this regard, the revealing of the diversity of linguistic means of conflict actions expression, their common and distinctive features, the functional peculiarities in the English language is considered to be the relevant task of modern linguistics, which is characterized by both theoretical and practical value. The purpose of the present article is to reveal the semantic peculiarities of the verbs denoting conflict actions with the highest degree of polysemy in modern English.

\section{Materials and Methods}

The verbs expressing conflict actions have been chosen as the material of our investigation which is represented by 300 lexical units possessing 1715 meanings.

So far as the verb from the point of view of the parts of speech hierarchy occupies one of the central positions to express actions, processes and states, the indication of conflict actions has a wide valency - it determines and distinguishes it from among other classes of words and still remains less studied in modern linguistics. Both the structure and the system of English are most comprehensively represented in the explanatory dictionaries, which serve as the most complete information banks in terms of lexical units: the more complete the dictionary, the more detailed is the correlation between their forms and content. Therefore, the source of our language material collection, study and classification is the Oxford English Dictionary in 20 volumes.

For the comprehensive comparative analysis of the lexico-semantic features of the verbs denoting conflict actions in modern English, a method of formalized analysis of lexical semantics in combination with the pure linguistic methods of research have been used. The procedure of formalized lexical semantics' analysis has been further developed and improved by prof. Fabian (1998). This method allows to disclose the semantics of the verbs denoting conflict actions in the English language by studying the correlations between the lexical units and their meanings, and singling out the special features of their seme stocks. The semantic correlations between the words in the language are best represented by the matrix method, which is a metalanguage for the description of conflict actions, and the matrix (see Table 1) is a model of interconnections' system between the lexical units, and the semantic structure of the words.

Table 1. Matrix fragment of the words denoting conflict actions in English

\begin{tabular}{|c|c|c|c|c|c|c|c|c|c|c|c|c|c|c|}
\hline Seme stock & 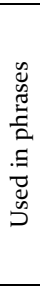 & $\begin{array}{l}\ddot{\infty} \\
\stackrel{0}{0} \\
\tilde{0} \\
\circ \\
\circ\end{array}$ & 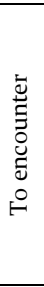 & 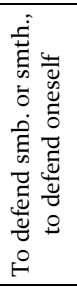 & 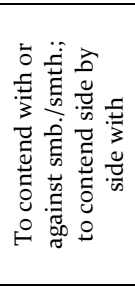 & 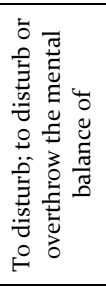 & 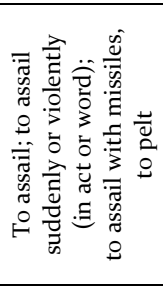 & 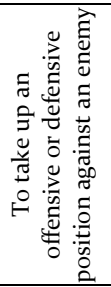 & 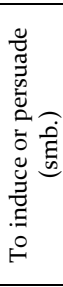 & 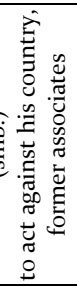 & 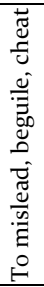 & 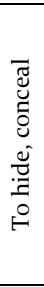 & 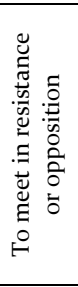 & 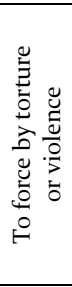 \\
\hline To stand & 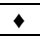 & + & 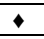 & 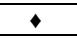 & 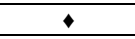 & & & $\bullet$ & & & & & & \\
\hline To turn & 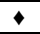 & 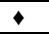 & & & & 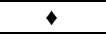 & $\downarrow$ & & & $\downarrow$ & $\downarrow$ & & & \\
\hline To keep & 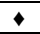 & & 4 & 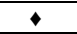 & & & & & & & & $\downarrow$ & 4 & \\
\hline To throw & 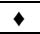 & & & & $\bullet$ & $\downarrow$ & $\downarrow$ & & & & & & & $\downarrow$ \\
\hline
\end{tabular}


In the matrix, semantic interrelations between the lexemes and their meaning components are fixed by means of lines and columns, where the vertical axe indicates the lexical stock and the horizontal one - the seme stock. The sign $(\diamond)$ denotes the relation existence between the lexical units and their meanings in the language under study. The words and their meanings in the matrix are grouped in the descending order due to their quantitative expression - from the most polysemantic to monosemantic ones.

\title{
3. Results and Discussion
}

The English language is not only a system of signs, a communication tool, a way of thinking and cognition, but first of all, it is the strongest, the richest and the most important link that unites a nation into one large family, one big historically significant whole. While studying the language, it is often difficult to interpret words because of their polysemy, which is an integral feature of the language.

Most of the lexical units denoting conflict actions in the language under study are characterized by their polysemy, which determines the nature of lexis, its ability to interact and to be in constant development. Due to it, words can be used in different contexts, get or lose certain meanings, and also to receive the opposite meanings. For this reason, a group of lexical units with the highest degree of polysemy makes the material of our study. Besides, "polysemy itself raises difficult theoretical and practical questions since all words have a certain plasticity that allows them to be used in different contexts" (Allan, 2016, p. 156). We also agree that "the concept of polysemy contrasts with the notion of vagueness" (Riemer, 2016, p. 234), the fact is that when studying languages, it is often difficult to study words because of their polysemy.

In every lifetime, there are difficult periods. For example, a person in puberty has a hormonal storm while teens have overwhelming energy, contrasts and ambitions concerning themselves and others. Moreover, such conflicts lead to the radical changes, which show the real person's character, his or her likes and dislikes, aspirations and dreams, attitudes to the outside world. Nowadays, there are conflicts which concern not only one person, family, country, but also prolonging UkrainianRussian conflict, which is accompanied by aggression and bloodbath. It is the result of numerous causes, the origins and possible further steps of which are difficult to determine. Therefore, "conflict life and conflict are two faces of the same coin: one cannot exist without the other" (Scarafile \& Gruenpeter Gold, 2016, p. 124).

The lexical stock of verbs denoting conflict actions in English is represented by 300 language units possessing 1715 lexical meanings. The verbs in English are divided into four groups according to the semantic characteristics and the degree of polysemy: the lexemes with the highest $(3,7 \%)$, middle $(20,3 \%)$, low degree of polysemy $(73,7 \%)$ and monosemantic ones $(2,3 \%)$ ( see Figure 1 ).

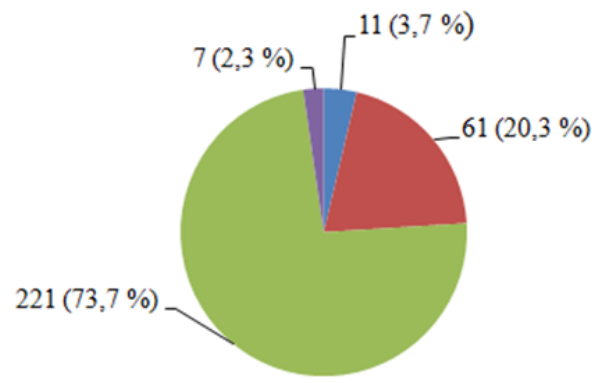

\author{
Words with the highest degree of polysemy \\ -Words with the middle degree of polysemy \\ Words with the low degree of polysemy \\ Monosemantic words
}

Figure 1. Quantitative characteristics of the English verbs denoting conflict actions 
The present article deals with the lexico-semantic analysis of the verbs with the highest degree of polysemy denoting conflict actions in modern English. The words in question comprise 11 language units characterized by $105-40$ meanings and make up 3,7 \% of the whole lexis under study. The words depict the views on the real life, relations, communication, arguing and cooperation between people not just within one family, company, country but the entire world.

The lexical units to throw, to stand, to keep, to turn, to settle, to hit, to round, to present, to answer, to smite, to charge belong to the ones denoting conflict actions and have both common and distinctive features. The ability to form word-combinations and phrases unites the verbs to throw, to stand, to keep, to turn, to settle, to hit, to round, to present, to answer, to charge. To throw oneself upon - to attack with violence or vigour; to fall upon; to throw (a) light on - to contribute to the elucidation of, to make clearer or plainer; to throw a punch - to deliver a blow with the clenched fist; throw by - to put aside with decision; to reject from present use; to discard; to throw down one's arms - to surrender; keep back - to restrain; to detain; to hold back forcibly; to retard the progress, advance, or growth of; keep down - to hold down; to hold in subjection or under control; keep out - to cause to remain without; keep up - to keep shut up or confined; to settle one's rest - to take up one's residence; to settle down - to subside into indolence or contentment; to settle for - to decide or agree on, to content oneself with; to hit anyone a blow - to strike him with a blow, to give him a blow; to be hard (sometimes heavily, badly) hit - to be severely or deeply affected by smth.; esp. to be seriously smitten by some adversity; to hit for six - to demolish an argument, scheme, etc., to vanquish; to deal a severe blow to; to answer back - to reply impertinently; to charge (a person) with (a fault, crime, etc.) - to accuse of; to be not (nought) to charge - to be of no importance, to matter not (Simpson \& Weiner, 1989).

The study of combinability potential of the verb is very important, as it is an objective means of its epidigmatic characteristics, evolution and paradigmatic relations with the other words within the group under study. In addition, the verb combinability "determines the specificity and regularity of the semantic relationships that arise in the process of functioning of the verbal system" (Ivanytska \& Ivanytska, 2018, p. 43).

The common feature of the lexical units to throw, to stand, to turn, to settle, to hit and to present is their ability to be used in figurative meanings. They reveal different shades of meanings of the words from habitual to violent actions against someone or something: to force, to distract, to confuse (someone), to vex, to upset, to break smth., to remain steadfast, to insist on smth., to revolve, to affect sensibly or painfully; to smite, to wound, to hurt (to throw - to cause to pass, go, fall or come into or out of some condition or relation; to cast, force, drive, plunge, thrust; to disconcert or confuse (someone), to upset; to stand - to remain stedfast, firm, secure, or the like; to make a point of, insist upon (doing smth.); to turn - to revolve (as time, etc.); to shape, form, or fashion artistically or gracefully; to revolve in the mind; to hit - to affect the conscience, feelings, comfort, prosperity, etc. of (any one) in a way analogous to physical hitting; to affect sensibly, painfully, or injuriously; to smite, wound, hurt; to discover a failing or a weak point).

Language units to throw, to stand, to turn, to hit and to smite have the common feature used in sport, which characterizes specific manifestations of the rivalry, courage, strength, struggle for success and recognition in sports (to put out of place or order by leaving behind in a chase or race; to distance, outpace (throw); to withdraw from a game, match, or race; to give up one's place in a team, crew, or 'side' (stand); to put (game, etc.) in a place to stock it (turn); to strike (the ball) with the bat: hence with the bowler as object (hit); to hit with great force; to defeat by hard hitting (smite). On the one hand, sports can be considered as the way of general therapy to resolve or avoid conflict actions but on the other, it can cause quarrels, arguing, displeasure, misunderstandings, and even lead to fights.

Semantics of the verbs to throw, to stand, to keep, to turn, to hit and to smite possesses negative connotations, denoting antagonistic intentions, hostility, active opposition etc. In its turn, the person in anger, offence and hatred, makes an irreparable mistake, resorts to force, quarrel, struggle or even fight rather than mobilize all his or her forces on its solving, which is expressed by 
the verbs: to throw and to stand - to contend with or against smb./smth.; to contend side by side with; to hit and to smite - to strike (smth.) against smth. else; (things) together; to strike with a weapon; to strike with smth. in hand or with a missile; to stand, to keep and to answer - to encounter; to throw, to turn, to round and to charge - to assail suddenly or violently (in act or word); to assail with missiles, impetuosity, to pelt.

The correlations between lexical units and their meanings have been presented by matrix which clearly defines the words' semantics in the form of both filled and unfilled cells (see Figure 1).

The semantic peculiarity of the group of words under study is that in addition to their common features, they have specific lexical meanings. For example, to throw (105 values) has a broad semantics which explicitly denotes the conflict actions: from the manifestation and embodiment of actions aimed at showing dislike, confrontation, dispute, argument, debate, gunfire, torture, refusing somebody in something, dismissing, reducing in rank, breaking (to go counter, to act in opposition, to exhibit dislike or aversion, to dispose, to quarrel with smb., to hurl a missile, a weapon, to force by torture or violence, to constrain, to direct words or an utterance towards smb. in hostility or contempt, to cause forcibly (smth.) to fall, to bring, knock, break, or cut down, to fall with violence or force, to disconcert or confuse (someone), to demolish, to lower in rank, to degrade, to humiliate, to discard, throw off, to get rid of, to shake off, to repudiate or reject the authority of, to eject, emit, give off, to cancel, etc.) to the actions of throwing, tossing, folding, felling, doing of something, formation, performing, lowering, turning, crossing, manufacturing, deflecting, etc. (to turn, to twist, to curl, to writhe, to twine, to cross, thwart, frustrate, to form, to fashion, to dispose, to arrange, to pass, to perform, to execute (smth.), to bring, to knock, to break, or cut down, to fell, to squander, to waste, to delay, to overcome, to introduce, insert, or interject in the course or process of something etc.).

The lexical unit to stand ( 98 meanings) forms three complete microsystems directly related to the conflict actions differing in manner: 1) to be in opposition, to stand against, to resist smb. or smth., especially, the enemy, natural phenomena, trials, etc. and to withstand something, for example, a blow or stroke, attack, shot, assault, siege, laughter, raillery, indignation, etc., to bear smth. (pain, harm), depend on smb. or smth (to confront, to face, to oppose, to persist in opposition, to encounter, to resist, to be exposed to, to beat, to disobey, to withstand, to hold out against smth. (a command), to put up with, to endure, to undergo, to put up with, to tolerate, to bear the brunt of, to present a firm front, to submit to, to be submitted to (smth.), to abide by (a judgement, decision, vote), to leave oneself dependent upon); 2) to stand in a vertical position, to be set, placed, fixed or situated in a specified position or aspect (to stand, to place, to remain motionless on one's feet, to cease walking or moving on, to remain erect on one's feet in a place, to exist, to set a thing upright, to be situated, to stay with); 3) to occupy a position, status in different areas of human activity (to appear as a candidate, to offer oneself as a candidate, to take up an offensive or defensive position against an enemy, to have opportunity to do smth., to be entered in a list, to occupy a specified place).

Furthermore, its individual meanings form the semantic microsystems and are at the same time in semantic relations. This feature characterizes all the verbs with the highest degree of polysemy.

The verb to stand can also form phrases and word combinations: to stand one's ground - to maintain one's position against attack or opposition; to stand in terms - to dispute or contend with (a person); to stand to one's arms - to form up with arms presented; to stand to one's guns, one's colours - to maintain one's position, not to retire before an attack; to stand up to - to confront or encounter boldly. This feature unites the analyzed word with other lexical units of the investigated group.

The following language unit to keep (61 meanings) is characterized by the polysemy and broad semantics as it has correlations with all the verbs with the highest degree of polysemy. Most often it is interrelated with the lexeme to stand expressing the support of someone or something in different situations, such as to keep something under control, to maintain hold of or to maintain a car, roads, home in good condition (to maintain in proper order, to maintain in a worthy or effective condition, to maintain, to uphold smth.) or to support a person in financial, medical, legal proceedings (to support (a person)), also to express an action associated with a persistent desire to continue something, such 
as practice, exercise, some action (to continue, persevere, go on smth., to continue to hold smth., to continue or persist in a course or action, to continue unimpaired) and to wait for a coming event or person, watch for stealthily with hostile purpose, to hide smb. or smth. from smb. or smth. (to watch for, wait for, await (smth. or smb.), to hide, to conceal).

The verb to keep is also semantically related to the words to stand and to answer as far as it does not denote conflict actions between individuals in the course of their social, psychological or physical interaction (to encounter; to meet in resistance or opposition), but the ones related to protection of a person or a thing from some injurious operation or accident (to guard, to protect (from smth.); to protect (smb.) by placing oneself in front of him. The latter one in relation with to keep and to settle possesses the semantics of the action to pay attention or regard to, to pay an account, bill, score.

The lexical unit under study is characterized by its individual semantics, especially reveals various actions and phenomena manifestation: not to come on; not to divulge; to stand to or dutifully abide by, to remain fixed or attached; to remain in favour or on good terms with; to stay away from; to stay at a distance; to retain; to intercept (a missile) etc.

The word to turn belongs to the first group of our language material, as it has 6o meanings, and has a wide-range semantics represented by the sets of meanings: to change or reverse course; to divert, to alter, to transfer, to pass, get beyond, to return, to get round and to change the direction or destination.

Here, the analysed verb to turn indicates an action that can cause conflict against a person, company, country, misleading smb. or smth. (to induce to act against smth., to adopt a different religion, or a godly life, to go over to another side or party, to direct against in feeling; to make antagonistic; to imbue with hatred or dislike; to mislead, beguile, cheat), the very process of this phenomenon (to oppose, to revolt, to take up an attitude of opposition, to change one's position in order to attack, to assail suddenly or violently (in act or word), to retort), and the action which help to avert the conflict by changing the course or direction of something (to deflect, to divert, to cause to go another way, to alter the course of, to change one's course of action, to direct one's mind, desire, or will to or from some person, thing, or action, to direct one's attention to a different subject) or to seek help from smb. (to resort, betake oneself, have recourse to (a person, etc.); to appeal to for help or support).

In addition, the lexical unit to turn contains indications of: 1) movement, rotation of something, such as movement round on an axis or about a centre, especially for opening or closing smth. as a key, door-handle, screw, tap, etc. (to rotate, revolve, to move round); 2) formation of something round for example by cutting with a chisel while rotating in a lathe (to form or shape by rotation);3) change of position (to change or reverse position, to shift, to alter the posture of an object by moving it through an angle); 4) change in a general sense, such as a change in a sentence, in mental balance, etc. (to change, transmute, to alter, to disturb or overthrow the mental balance of, to make mad or crazy, distract, dement, infatuate, to change colour). The last one semantically unites the analysed verb with the lexical unit to throw.

Being used in all sorts of phrases, the word to turn gets additional semantic meanings: to turn into ire - to become angry; to turn a deaf ear - to refuse to listen; turn one's hand - to make an attack upon; turn head - to turn and face an enemy; turn by - to set aside, reject; turn down - to put down, send to a lower position; to turn up one's heels - to die. The word semantics development and its connections with other parts of speech form another specific feature of the lexical units in English.

The lexeme to settle ( 57 meanings) is characterized by positive evaluative semantics, rendering the meanings of completing action, setting up of something, formation, sinking into smth. (the mind or heart), settlement of people to a certain territory, calming, recovering etc. (to seat, to dispose in order, to furnish (a place) with inhabitants or settlers, to establish, to set up smth., to decide, to fix, implant smth., to sink deeply into smth., to lower in condition, to calm down, to subside, to become composed, to quiet, to tranquillize smth., to recover from smth., to adopt firmly (smth.), to secure or confirm a person in a position of authority).

It is widely known that any conflict actions have certain consequences. Thus, in case of wrong 
resolution of conflict actions, anxiety, loneliness, high blood pressure, stress, low productivity, illness etc. are inherent in human nature. If the conflict actions resolution is constructive, then calmness, gaiety, intense vitality, physical or mental activity, efficiency, growing of positive personal qualities, health will accompany the person.

Positive conflict resolution is revealed by the lexical unit to settle with the help of the meanings denoting effective communication and reaching a compromise through the settle of a dispute, conflict, solution, solving a disagreement, discussion points, differences in views, etc. (to end an argument, to come to a fixed conclusion on smth.; to agree to stop arguing, to arrange matters in dispute, to come to terms or agreement with a person, to decide (a case) by arrangement between the contesting parties, to make an arrangement, compound with smb.).

In the semantics of the verb to settle, there is also a hint of compulsion on someone to do something (to compel to cease from opposition or annoyance; to silence, nonplus). Sometimes it is the only way to escape from negative consequences of some actions and to regulate relationships as well as to establish justice. The common feature of the lexical unit to settle and the words in question is their ability to be widely used in word combinations and figurative meanings.

If the lexeme to settle contains the semantics which expresses the end of an action, then the language unit to hit ( 53 meanings) rather reveals the essence of the action process - to strike, to get at or reach with a blow, to give a blow to smth., to come with forcible impact against/upon, to deliver a blow/stroke, to occur to a person, to rob, to kill, to throw, to come upon, to meet with, to agree together, to direct one's aim or course, to agree, to thrust in, to push in with a stroke, to succeed in getting at or upon, to describe, to represent, to reproduce, to strike out, elicit, to strike out with the first, to speed up, to put on pressure, which semantically links the language unit to hit with the corresponding verbs to throw and to keep.

The common feature of the word to hit with the verbs under study is the ability to be used in a figurative sense denoting criticism, humiliation and laughing at a person or thing (to criticize, make fun of or ridicule smth.). Thus, lexeme to hit is a multi-faceted phenomenon, representing the expression of striking, knocking, throwing and criticizing to the action of getting an agreement.

The lexical unit to round (47 meanings) establishes the relations with the words to round and to stand denoting an action of discussing important, intricate unsettled questions, problems, secrets, sharing ideas or decisions about something (to talk about or over; to discuss; discuss at large, insist on (a topic, a point in argument)). The lexemes to round and to throw indicate actions such as: to form; to form into a cylinder; to form or fashion by means of a rotary or twisting motion, whereas to round and to turn are united by the lexical meaning (to become), which can be used in different situations from to become an informer, to become the cause or occasion of to the shape, nature, hair colour changing - to become round, circular or spherical; to change into, become of (a specified nature, form, or aspect), become of a different colour.

The verb under study is characterized by individual semantics which explicitly denotes conflict actions depicting the process of criticizing smb. or smth. severely, using rude, abusive words or attacking each other violently using weapons (to turn round on; to assail, assault, esp. with words; to abuse, berate). The following semantic meanings of the language unit to round have positive connotations: to make round, to draw together, or expand, into a rounded form, to make convex, to surround or encircle, to encompass with something, to pass or travel round a place or the world, to finish off, to end with something, to cause to turn round or move in a circle, to grow or develop to a full round form, to go about, to whisper, to speak in a whisper, to converse or talk privately, to tell, to say, to take or give as counsel etc. The characteristic feature of the verb under study is the ability to form phrases and word combinations: to round out - to finish or complete; to fill out, make plump; to round over - to turn over so as to close at the end; to present oneself - to come into the presence and sight of another or others, or into a particular place, esp. in a formal manner; to appear, attend.

To present and to answer have 46 meanings each, but they qualitatively different. These verbs have a connection with the lexemes to throw, to keep, to smite and to charge depicting an action of giving something to someone (to give (smth.)). Analyzing the semantics of words denoting conflict 
actions, we note that language units as components of the system and structure of language are described in Oxford English Dictionary by means of repeating one and the same features to a greater or lesser extent. This kind of repetition expresses the continuity of the lexical semantics' structural organization.

The polysemantic verb to answer combines three semantic microsystems which are synonymously related: 1) to fulfill obligations, to answer to a charge, to be responsible for, to defend someone in a court of law, to accede to a request, to serve the purpose (to make a statement in reply to a legal charge, to be liable so to do, or to suffer the consequences, to speak in reply or opposition to a charge or accusation, to defend oneself, to be responsible or accountable for, to satisfy a person of or for the claim, to recompense, to fulfill wishes, hopes, expectations) and 2) to respond, to answer, to correspond, to reply to a question in a verbal or written form, comments, requests, orders, directions, to make correspondence (to answer a question, remark, etc., to speak or write in reply to a question, remark, or any expression of desire or opinion, to respond, to rejoin, to give an answer to smth., to reply to what is practically a request, to answer the door, the bell, to make a sign of any kind in response to, or acknowledgment of, any signal), and also 3) to correspond to something, to serve, to act according to something, to do smth. as a reaction to smth. that has been done or said, to have a counteraction or an appropriate reaction to something (to answer in similarity, to correspond, to act in conformity with (smth.), to obey, to act in sympathy with, or in response (to), to repeat the action of, to give back in kind, to return the hostile action of (a person), meet in fight, encounter, to agree to). These meanings are conventionally referred to the 'actions in jurisprudence', 'domestic actions' and 'response actions to something that has been done' microsystems.

Furthermore, the lexical unit to present has a broad semantics: from giving the present or gift, introducing, greeting, delivering, offering to performing and acting a role on the stage, describing, giving a particular direction or position, designating something with certain actions, accusing and charging, making complaints against smb. (to make present to, to bring into the presence of, to offer, to give greeting, to show, to exhibit, to display, to view, to notice, to show itself, to appear, to be a picture of, to stand for, to denote, to be a sign of, to deliver, to convey, to bestow smth. upon, to endow, to introduce, to represent (a character) on the stage, to bring a formal charge or accusation against a person, to charge formally, to make a formal statement of, to submit (a fact or a request, complaint, etc.)).

The word to smite (44 meanings) is semantically related to the verb to charge as far as it denotes an attack with hostile actions, with reasoning or argument and it can be used in military sphere, also it can be said of a powerful animal rushing at smb., or of players at football, etc. (to attack, to attack impetuously). The lexeme to smite has connections with the lexical unit to hit, depicting a mental, sensible, painful, injurious etc. affect on smb. or smth. and expressing the force, strength, violent, defeat by hard hitting, striking smb. or smth. (to affect suddenly, grievously, painfully, to affect in a particular way and to hit (smth.), to hit with great force) and with the verb to throw in the meanings to produce smth., to produce (a wound, etc.) by smiting; to break down; to shoot. The words to smite and to answer indicate the action such as to discharge (smth.), whereas to smite and to turn are united by the lexical meaning to imbue suddenly or strongly with some feeling or sentiment, to imbue with hatred or dislike.

The language unit to smite has its individual semantics, possessing negative connotations, which bring a sorrow, a distress, a hatred, an injure, a tornment and a physical harm to someone (to knock, to beat, to cut off, to blemish, to infect, to occur suddenly to one, to give pain to one's heart, to change, to pass, fall, into something, to give a blow, etc.). One of the meanings is to strike, to engage in or fight (a battle), to come together (or samen) in conflict, to strike or dash on or against somentihg, to knock, beat or strike down, to the earth or ground, which brings the lexical unit under study closer to the verb with the highest degree of polysemy to hit.

The verb to charge forms four semantic microsystems which are related by synonymous links: 1) to load e.g. a vehicle, ship, etc., to cause to bear, to hold, to receive smth. (to lay or place (smth.) as a load upon; to lade; to carry as a load or lading; to put in or on (a thing); to cause to take or receive; to 
fill (any substance) with other matter, diffused or distributed throughout it) and 2) to load heavily, to burden with smth., such as expense, tribute, exactions, etc, to put anything onerous, troublesome, hateful upon, to blame, causing in this way someone to worry, to suffer, to have a pain also to lay a command or injunction upon (to lay too heavy a load upon; to overload; to press hard; to impose a duty, task, or responsibility upon; to burden, entrust, commission with; to command, order, enjoin; to exhort authoritatively; to lay blame upon, to censure; to bring an accusation against, accuse), 3) to attach significance, value to smth; to think that smth. is important or true and that it should be considered seriously (to attach weight or importance to) and in negative sense (to make no account of, set at nought), 4) to attack in a hostile manner (to place (a weapon) in position for action; to direct and aim (a blow or stroke); to rush against or upon, with all one's force, in a hostile way; to bear down upon, to make a violent onset on).

The language unit to charge has semantic interconnections with the lexemes to hit, to present, to smite denoting the actions such as: to deliver; to deliver formally to the proper quarter for acceptance; deliver a blow or stroke, at, on, or upon smth.; to deliver an official or formal instruction or exhortation to and with the verbs to throw, to answer which express the action of causing someone or smth. to be in a particular condition (to render; to render inoperable (smth. mechanical); to render prominent or distinct; to render replete). The lexeme to charge is also semantically bound with the word to stand, characterizing a strong person who insists on the recognition of his/her rank, possessions, respect, etc. (to demand, to claim respect or credit for one's rights, qualities, dignity). The lexical units to charge and to keep are united by the meaning (to care for, regard, reck) that shows an individual as a caring person who worries about others, for whom every detail is important and who is always ready to help.

Our research showed that in English dictionary under study, semantic continuity is mostly represented by the formulas of interpretation, which, when compared, make us sure that the lexical meanings of English words are revealed by the principle of explaining one word through the second, the second through the third, and so on and so forth. As a result, when determining the lexical unit semantics in its connection to another or other words, we establish not only the presence (absence) of common semantic components, but also the degree of their manifestation. This chain correlation constitutes the semantic regularity of the formation of the verbs denoting conflict actions in English.

\section{Conclusions}

The characteristic features of the lexical units denoting conflict actions are a tendency to the polysemy, the ability to form microsystems, to be used in both direct and figurative meanings, and the word semantic development in the background of its combinability with other parts of speech. At the same time the semantic peculiarity of the words with the highest degree of polysemy to throw, to stand, to keep, to turn, to settle, to hit, to round, to present, to answer, to smite and to charge is that in addition to their specific lexical meanings, they also have common features. They include the struggle of a person for or against smb./smth. with the purpose of achieving their goals; the dispute or contend between smb./smth., for instance, a disagreement between management and employees; a violent physical or verbal attack, assault or strike in order to save the family, relationships, territory, country; to defend smb. or smth. by speaking or writing in favour of smb. or smth.; to agree with smb. or smth. in order to adjust differences, to resolve the conflict, to reach a compromise and effective communication.

In this respect language is certainly figures central in our lives. It is the best way of expressing our very being, coming to terms with the whole world and making contact with other people. The language serves as a means of communication and cognition, as it allows us to think for ourselves and to collaborate with others in the society.

The complex study of the lexical units denoting conflict actions allowed to define their role, place and functioning in modern English. The analysis also has shown that English verbs under study on the one hand, are independent elements of the group, and are semantically related with each 
other, adding specific characteristics to reflect the forms and the ways of their expression, on the other.

Semantics of conflict actions in modern English is represented by the verbs to throw, to stand, to keep, to turn, to settle, to hit, to round, to present, to answer, to smite, to charge and it is revealed by means of expressing force, attack, strike, argument, violent actions against someone or something, hurt, pain, wound, dislike, confrontation, dispute, debate, gunfire, torture, reducing in rank as well as supporting somebody in something, keeping something under control, waiting for smb. or smth. etc.

Complex study of the lexical units with the highest degree of polysemy denoting conflict actions in English with the help of methodology based on formalized analysis of lexical semantics opens new and wide possibilities for the further investigation of language fragments belonging to related as well as non-related languages.

\section{References}

Abdou, J. M., \& Keiding, H. (2019). A qualitative theory of conflict resolution and political compromise. Mathematical Social Sciences, 98, 15-25. https://doi.org/10.1016/j.mathsocsci.2019.01.0o1

Abu-Bader, S., \& Ianchovichina, E. (2019). Polarization, foreign military intervention, and civil conflict. Journal of Development Economics. 141, 102248. https://doi.org/10.1016/j.jdeveco.2018.06.006

Aguirre, A. (2016). The risk of civil conflicts as a determinant of political institutions. European Journal of Political Economy, 42, 36-59. https://doi.org/10.1016/j.ejpoleco.2016.01.002

Allan, K. (Ed.). (2016). The Routledge Handbook of Linguistics. London, New York: Routledge.

Arieli, O. (2015). Conflict-free and conflict-tolerant semantics for constrained argumentation frameworks. Journal of Applied Logic, 13(4), Part 2, 582-604. https://doi.org/10.1016/j.jal.2015.03.005

Baumann, R., Dvořák, W., Linsbichler, T., Spanring, C., Strass, H., \& Woltranc, S. (2016). On rejected arguments and implicit conflicts: The hidden power of argumentation semantics. Artificial Intelligence, 241, 244-284.

Berry, I., \& Berrang-Ford, L. (2016). Leishmaniasis, conflict, and political terror: A spatio-temporal analysis. Social Science E Medicine, 167, 140-149. https://doi.org/10.1016/j.socscimed.2016.04.038

Burbekova, S., \& Nurzhanova, A. (2014). Problems of Translation Theory and Practice: Original and Translated Text Equivalence. Procedia - Social and Behavioral Sciences, 136, 119-123.

Chandler, D. (2017). Semiotics: The Basics. (3d ed.). New York: Routledge.

Charalambous, C., Zembylas, M., \& Charalambous, P. (2016). Diversity and conflict: Negotiating linguistic, ethnic and emotional boundaries in Greek-Cypriot literacy classrooms. Linguistics and Education, 35, 50-62.

De Dreu, C. K. W., \& Gelfand, M. J. (Eds.). (2008). The Psychology of Conflict and Conflict Management in Organizations. New York, Lawrence London: Erlbaum Associates.

Euwema, M. C., \& Van Emmerik, IJ. H. (2007). Intercultural competencies and conglomerated conflict behaviors in intercultural conflicts. International Journal of Intercultural Relations, 31(4), 427-441. https://doi.org/10.1016/j.ijintrel.2006.11.0o1

Fabian, M. (1998). Etiquette lexis in Ukrainian, English and Hungarian languages. Uzhhorod: IVA.

Fabian, M. (2017). Etiquette in modern English: social setting. Contemporary Studies in Foreign Philology, 15, 10-20.

Glass, C., \& Cook, A. (2017). Appointment of racial/ethnic minority directors: Ethnic matching or visibility threat? Social Science Research, 61, 1-10. https://doi.org/10.1016/j.ssresearch.2016.07.004

Ivanytska, N. B., \& Ivanytska, N. L. (2018). Synagmatic dimension of Ukrainian and English verbs: the typology of exponents of correlation. Current trends in language development, 17(9), 43-56.

Lebedko, M. G. (2014). Interaction of Ethnic Stereotypes and Shared Identity in Intercultural Communication. Procedia - Social and Behavioral Sciences, 154, 179-183.

Massey, Z. B., \& Miller, C. H. (2018). Case studies on interethnic conflict: A theoretical integration. International Journal of Intercultural Relations, 66, 130-147. https://doi.org/10.1016/j.ijintrel.2018.04.006

Melin, M. M. (2016). Business, peace, and world politics: The role of third parties in conflict resolution. Business Horizons, 59(5), 493-501. https://doi.org/10.1016/j.bushor.2016.03.013

Naveh-Kedem, Y., \& Sverdlik, N. (2019). Changing prosocial values following an existential threat as a function of political orientation: Understanding the effects of armed conflicts from a terror management perspective. Personality and Individual Differences, 150, 109494. https://doi.org/10.1016/j.paid.2019.07.004

Nordquist, R. (2019). Observation on What Is Language. Available: https://www.thoughtco.com/what-is-alanguage-1691218 (October 29 2019). 
Ran, Y., \& Zhao, L. (2018). Building mutual affection-based face in conflict mediation: A Chinese relationship management model. Journal of Pragmatics, 129, 185-198. https://doi.org/10.1016/j.pragma.2018.01.013

Riemer, N. (Ed.). (2016). The Routledge Handbook of Semantics. London, New York: Routledge.

Sarpiya, S. K. (2018). A Semiotic Approach to Conflict Transformation: Can Signs and Symbols Help Make Peace? Portland: George Fox University.

Scarafile, G., \& Gruenpeter Gold, L. (Eds.). (2016). Paradoxes of Conflicts. Cham: Springer International Publishing. Simpson, J., \& Weiner, E. (Eds.). (1989). Oxford English Dictionary: in 20 vol. Oxford: Clarendon Press.

Thiessen, C., \& Darweish, M. (2018). Conflict resolution and asymmetric conflict: The contradictions of planned contact interventions in Israel and Palestine. International Journal of Intercultural Relations, 66, 73-84. https://doi.org/10.1016/j.ijintrel.2018.06.0o6.

Volpe, V. V., Holochwost, S. J., Cole, V. T. \& Propper, C. (2019). Early growth in expressive communication and behavior problems: Differential relations by ethnicity. Early Childhood Research Quarterly, 47, 89-98.

Wiezbicka, A. (1996). Semantics: primes and universals. Oxford: Oxford University Press. 